\title{
Genetically proxied milk consumption and risk of colorectal, bladder, breast, and prostate cancer: a two-sample Mendelian randomization study
}

Susanna C. Larsson ${ }^{1,2^{*}}$ (D) Amy M. Mason ${ }^{3,4}$, Siddhartha Kar ${ }^{5}$, Mathew Vithayathil ${ }^{6}$, Paul Carter ${ }^{7}$, John A. Baron ${ }^{1,8,9,10}$, Karl Michaëlsson ${ }^{1}$ and Stephen Burgess ${ }^{7,11}$

\begin{abstract}
Background: Observational studies have shown that milk consumption is inversely associated with colorectal, bladder, and breast cancer risk, but positively associated with prostate cancer. However, whether the associations reflect causality remains debatable. We investigated the potential causal associations of milk consumption with the risk of colorectal, bladder, breast, and prostate cancer using a genetic variant near the LCT gene as proxy for milk consumption.

Methods: We obtained genetic association estimates for cancer from the UK Biobank ( $n=367,643$ women and men), FinnGen consortium ( $n=135,638$ women and men), Breast Cancer Association Consortium ( $n=228,951$ women), and Prostate Cancer Association Group to Investigate Cancer Associated Alterations in the Genome consortium ( $n=140,254$ men). Milk consumption was proxied by a genetic variant (rs4988235 or rs182549) upstream of the gene encoding lactase, which catalyzes the breakdown of lactose.

Results: Genetically proxied milk consumption was associated with a reduced risk of colorectal cancer. The odds ratio (OR) for each additional milk intake increasing allele was 0.95 (95\% confidence interval [CI] 0.91-0.99; $P=$ 0.009). There was no overall association of genetically predicted milk consumption with bladder (OR $0.99 ; 95 \% \mathrm{Cl}$ 0.94-1.05; $P=0.836)$, breast (OR 1.01; 95\% Cl 1.00-1.02; $P=0.113)$, and prostate cancer (OR 1.01; 95\% Cl 0.99-1.02; $P=0.389)$, but a positive association with prostate cancer was observed in the FinnGen consortium (OR 1.07; $95 \% \mathrm{Cl}$ $1.01-1.13 ; P=0.026)$.
\end{abstract}

Conclusions: Our findings strengthen the evidence for a protective role of milk consumption on colorectal cancer risk. There was no or limited evidence that milk consumption affects the risk of bladder, breast, and prostate cancer.

Keywords: Cancer, Genetic variants, Milk consumption, Mendelian randomization, Neoplasm

\footnotetext{
* Correspondence: susanna.larsson@ki.se

${ }^{1}$ Unit of Medical Epidemiology, Department of Surgical Sciences, Uppsala University, Uppsala, Sweden

${ }^{2}$ Unit of Cardiovascular and Nutritional Epidemiology, Institute of Environmental Medicine, Karolinska Institutet, 17177 Stockholm, Sweden

Full list of author information is available at the end of the article
}

C The Author(s). 2020 Open Access This article is licensed under a Creative Commons Attribution 4.0 International License, which permits use, sharing, adaptation, distribution and reproduction in any medium or format, as long as you give appropriate credit to the original author(s) and the source, provide a link to the Creative Commons licence, and indicate if changes were made. The images or other third party material in this article are included in the article's Creative Commons licence, unless indicated otherwise in a credit line to the material. If material is not included in the article's Creative Commons licence and your intended use is not permitted by statutory regulation or exceeds the permitted use, you will need to obtain permission directly from the copyright holder. To view a copy of this licence, visit http://creativecommons.org/licenses/by/4.0/. The Creative Commons Public Domain Dedication waiver (http://creativecommons.org/publicdomain/zero/1.0/) applies to the data made available in this article, unless otherwise stated in a credit line to the data. 


\section{Background}

Milk products are major components of the traditional Western diets and are rich sources of essential nutrients [1]. The association between self-reported milk consumption and cancer risk has been extensively studied. Available observational data indicate that milk consumption is associated with a reduced risk of colorectal cancer [2-7], an association that may be mediated, at least in part, by calcium [7-10]. The World Cancer Research Fund and American Institute for Cancer Research have concluded that there is convincing evidence that consumption of dairy foods and taking calcium supplements decrease the risk of colorectal cancer [7]. Inconclusive observational evidence further suggests that milk consumption is inversely associated with risk of bladder [4, $11,12]$ and breast cancer $[4,7,13,14]$, positively associated with prostate cancer $[4,7,15-17]$, but not associated with other cancers [4, 7, 18, 19]. However, as observational studies are susceptible to methodological biases, particularly confounding and reverse causality, the causal role of milk consumption for cancer risk remains unestablished.

Milk sugar (lactose) is digested by the enzyme lactase, which is encoded by the lactase gene (LCT) and produced by cells in the small intestine. A single nucleotide polymorphisms (SNP) upstream of the LCT gene is associated with lactase persistence (the continued activity of the lactase enzyme in adulthood) and with higher milk consumption in European populations [20, 21]. We assessed the potential causal associations of milk consumption with the risk of colorectal, bladder, breast, and prostate cancer using the $L C T$ gene variant as proxy for milk consumption.

\section{Methods}

\section{Outcome data sources}

Genetic association estimates for colorectal, bladder, breast, and prostate cancer were estimated in the UK Biobank cohort, which enrolled about 500,000 adults (37 to 73 years of age) between 2006 and 2010 [22]. In the present analysis, we included 367,643 unrelated participants of European ancestry to diminish population stratification bias and used follow-up data to March 31, 2017. Classification of each cancer site has been reported previously [23]. Analyses of genotype-cancer associations were done only in women for breast cancer and only in men for prostate cancer. We adjusted the association estimates for age, sex (in analyses of colorectal and bladder cancer), and the first ten genetic principal components through logistic regression.

We additionally obtained summary-level data (i.e., beta coefficients and standard errors) for genetic associations with colorectal, bladder, breast, and prostate cancer from the FinnGen consortium (including up to 135,638 women and men of Finnish ancestry) [24]. The equivalent summary-level data for breast and prostate cancer were acquired respectively from the Breast Cancer Association Consortium (BCAC) (including 228,951 women of European ancestry) [25] and the Prostate Cancer Association Group to Investigate Cancer Associated Alterations in the Genome (PRACTICAL) consortium (including 140,254 men of European ancestry) [26]. All genetic association estimates were calculated by logistic regression comparing cases and controls and adjusted for genetic principal components (the first ten in the FinnGen consortium and $\mathrm{BCAC}$, and the first seven in the PRACTICAL consortium). Some studies further adjusted for study-relevant covariates, such as age, sex (in analyses of colorectal and bladder cancer in the FinnGen consortium), country, and genotyping batch.

The UK Biobank and studies included in the consortia had been approved by an ethical review board, and all participants provided informed consent. The current analyses were approved by the Swedish Ethical Review Authority.

\section{Genetic instrument}

As a genetic instrument for milk consumption in our primary analyses, we used rs4988235, which is located upstream from the LCT gene and is associated with milk consumption in European populations [20, 21]. In a subcohort of 12,722 participants of the European Prospective Investigation into Cancer and Nutrition-InterAct study, the median milk consumption was $162 \mathrm{~g} /$ day (25th to 75 th percentile, 37 to $300 \mathrm{~g} /$ day) and each additional milk intake increasing allele of rs4988235 was associated with an increase in milk consumption of $17.1 \mathrm{~g} /$ day $\left(P=2 \times 10^{-7}\right)$ [20]. In a population-based cohort study of 73,715 Danish individuals, milk consumption increased with 0.58 (95\% CI 0.49-0.68) glasses/week $\left(P=9 \times 10^{-36}\right)$ for each additional milk intake increasing allele of rs4988235 [21]. In the Danish cohort, the SNP explained $2 \%$ of the variance in milk intake, and the Fstatistic was 515 [21]. Rs4988235 was not available in the FinnGen consortium, and a proxy SNP (rs182549) in complete linkage disequilibrium was used.

Another SNP (rs3754686) nearby the LCT gene has been shown to be strongly associated with milk consumption in Mediterranean and American populations [27]. Rs3754686 was available in all data sources and was in strong linkage disequilibrium with rs4988235 $\left(R^{2}=0.71\right.$ in the CEU [Utah residents from North and West Europe] population, 0.95 in the British population, and 0.77 in the Finnish population; LDlink version 4.2 [28]). Rs3754686 was used as an instrument for milk consumption in a complementary analysis. 


\section{Statistical analysis}

Odds ratio (OR) estimates were reported per additional milk intake increasing allele. Estimates from the different data sources were combined using fixed-effects metaanalysis. The amount of heterogeneity between estimates was quantified using the $I^{2}$ statistic [29]. All analyses were conducted using Stata/SE 14.2 (Stata Corporation, College Station, TX, USA).

\section{Results}

Genetically predicted milk consumption was inversely associated with colorectal cancer risk in the combined analysis of the UK Biobank and FinnGen consortium (Fig. 1). The OR for each additional milk intake increasing allele was 0.95 (95\% confidence interval [CI] $0.91-$ $0.99 ; P=0.009)$, without evidence of heterogeneity between estimates from the two studies $\left(I^{2}=0 \%\right)$. Genetically predicted milk consumption was not associated with bladder cancer (OR 0.99; 95\% CI 0.94-1.05; $P=0.836$; $\left.I^{2}=0 \%\right)$ or breast cancer (OR 1.01; 95\% CI 1.00-1.02; $P=0.113 ; I^{2}=5.4 \%$ ) (Fig. 1 ). In the BCAC, results were null for both estrogen receptor-positive (OR 1.00; 0.98$1.02 ; P=0.999)$ and estrogen receptor-negative (OR 1.01;
95\% CI $0.98-1.04 ; P=0.494)$ breast tumors. No overall association was observed between genetically predicted milk consumption and prostate cancer (OR 1.01; 95\% CI $0.99-1.02 ; P=0.389)$, but there was moderate heterogeneity among estimates from different data sources $\left(I^{2}=\right.$ $54 \%$ ) and a positive association was observed in the FinnGen consortium (OR 1.07; 95\% CI 1.01-1.13; $P=0.026$ ) (Fig. 1).

Results were similar when using rs3754686 as an instrument for milk consumption. The ORs in these analyses for each additional milk intake increasing allele were 0.94 (95\% CI $0.90-0.90 ; P=0.003)$ for colorectal cancer, 1.01 (95\% CI 0.95-1.07; $P=0.767$ ) for bladder cancer, 1.00 (95\% CI $0.99-1.01 ; P=0.974$ ) for breast cancer, and 1.01 (95\% CI 0.99-1.03; $P=0.265$ ) for prostate cancer.

\section{Discussion}

This genetic study found that higher milk consumption was associated with a reduced risk of colorectal cancer, consistent with findings of observational studies [2-7]. However, our findings do not support observational findings that higher milk consumption is associated with

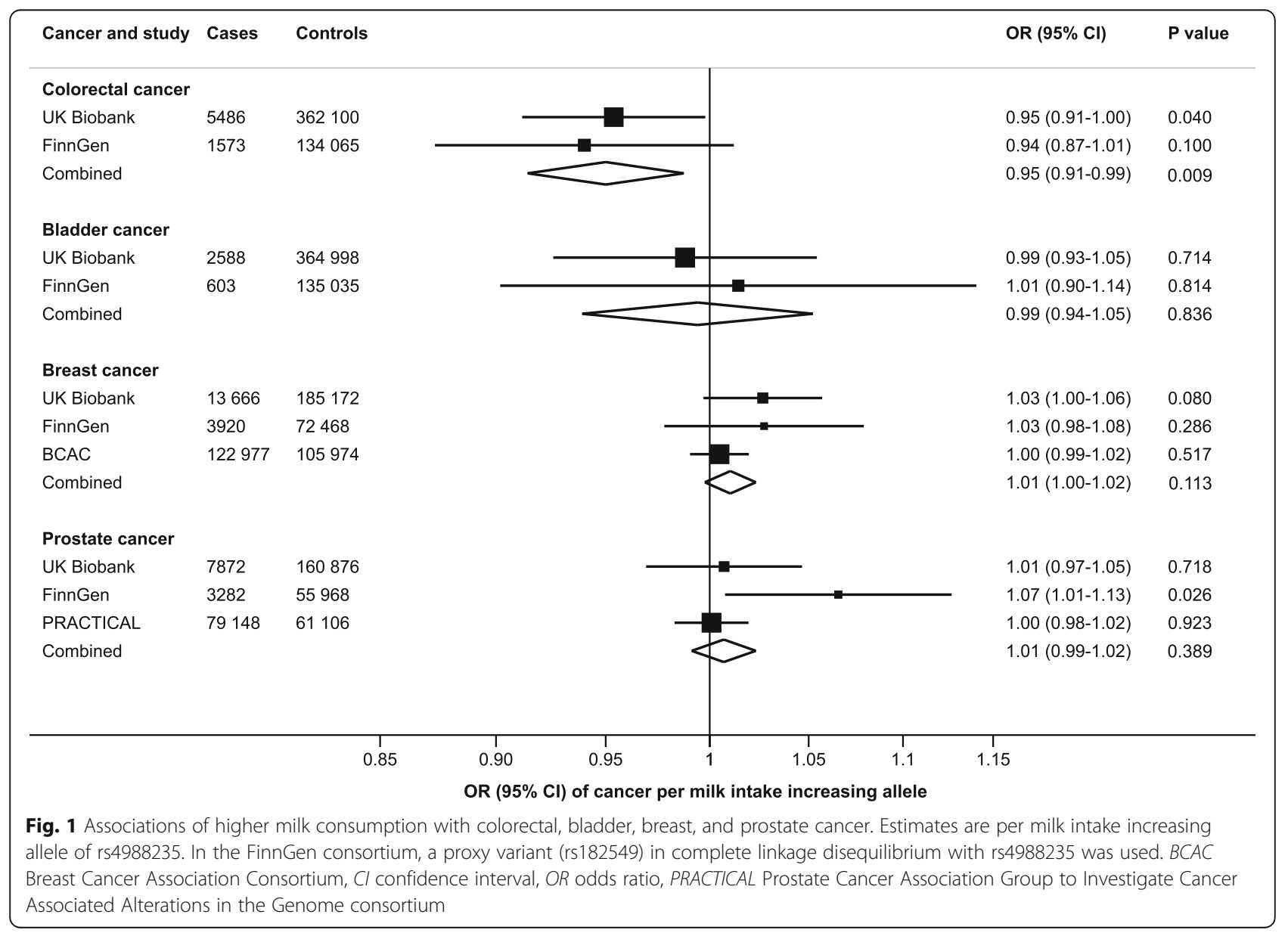


a lower risk of bladder and breast cancer or with a higher risk of prostate cancer, though a positive association between genetically predicted milk consumption and prostate cancer was found in the FinnGen consortium. For bladder cancer, observational studies have reported a protective association mainly with the consumption of fermented milk products (cultured milk, yogurt, and cheese) $[12,30]$. The lactase persistence variant is not associated with yogurt and cheese consumption [20, 21].

Studies of genetically predicted milk consumption in relation to site-specific cancers are scarce. No association was observed between rs4988235 and colorectal cancer in small case-control studies conducted in Turkey (44 cases and 48 controls) [31] and Italy (306 cases and 311 controls) [32]. Lactase persistence was non-significantly positively associated with prostate cancer risk in a meta-analysis of three studies, including a case-control study nested in the European Prospective Investigation into Cancer and Nutrition study (630 cases and 873 controls) and case-control studies of Finnish (1229 cases and 473 controls) and Swedish (2924 cases and 1842 controls) men [33]. The combined OR was 1.12 (95\% CI 0.96-1.32) [33] and ranged from 1.06 to 1.16 in individual studies $[33,34]$. This finding is consistent with the result observed in the FinnGen consortium. The reason for the disparate findings for rs4988235 and prostate cancer risk might be related to different amounts of milk consumed in different populations. Finland is the country with the highest per capita milk consumption and Sweden also has high consumption [35]. If there is a threshold effect of milk consumption on prostate cancer risk, an association between the lactase persistence variant and prostate cancer might only be seen in populations with high milk consumption.

The observed protective association between milk consumption and colorectal cancer may be mediated, at least partly, by calcium. Calcium supplementation has been demonstrated to reduce the risk of colorectal adenomas in randomized controlled trials [8] and colorectal cancer in observational studies $[9,10]$. In one of the trials, the protective effect of calcium supplementation on colorectal adenomas was confined to individuals with a normal body mass index [36]. Calcium may have a local protective effect on colorectal cancer by binding secondary bile acids and free fatty acids in the lumen of the bowel, thereby inhibiting their toxic effects on colonocytes and suppressing mucosal proliferation [37, 38]. Stimulation of the calcium-sensing receptor in colonocytes is another possible mechanism [39]. Calcium supplementation has also been shown to lead to a nonsignificant increased expression of tight junction proteins, suggesting that calcium may play a role in maintaining the integrity of the intestinal mucosal barrier [40].

Other compounds in milk that might protect against colorectal cancer include butyric acid (a short-chain fatty acid), conjugated linoleic acid, sphingolipids, and lactoferrin $[37,38,41]$. Almost $70 \%$ of the fat in milk is saturated of which about $11 \%$ comprises short-chain fatty acids (half of which is butyric acid) [42]. Milk fat also contains conjugated linoleic acid [42]. The anticarcinogenic effects of this fatty acid have been demonstrated in animal models [37], but human data are limited to a Swedish cohort study which revealed a statistically significant inverse association between conjugated linoleic acid intake and risk of colorectal cancer [43]. Lactoferrin is an iron-binding glycoprotein present in human and bovine milk. It enhances immune function and inhibits colorectal carcinogenesis in animal models [44]. In addition, a randomized controlled trial found that orally administered lactoferrin for 12 months retarded the growth of adenomatous colorectal polyps in the subgroup of participants 63 years of age or younger [44]. Milk consumption may also influence colorectal cancer risk by altering the gut microbiota. Higher milk consumption has been associated with greater microbiota richness and more abundant Faecalibacterium and Fusobacterium but less Bacteroides in humans [45]. A recent study showed that supplementing the diet of aging mice with bovine milk increased intestinal levels of short-chain fatty acids through modulation of gut microbiota [46].

There is suggestive or weak evidence from observational studies that milk consumption might increase prostate cancer risk via calcium [7, 17] and insulin-like growth factor 1 [47]. A recent Mendelian randomization study showed that genetically predicted insulin-like growth factor 1 levels were significantly positively associated with prostate cancer in the UK Biobank and nonsignificantly positively associated with prostate cancer in the PRACTICAL consortium and BioBank Japan [48]. Milk is also a rich source of phosphorus, which was observed to be positively associated with the risk of prostate cancer in a cohort of US health professionals [49].

Findings from a Mendelian randomization study can be biased if the genetic instrument affects the outcome through a pathway other than via the exposure of interest. In this case, it is plausible that a high milk consumption results in lower or higher consumption of other foods. In fact, the milk intake increasing allele of rs4988235 has been shown to be modestly associated with lower consumption of fruits $(-7.0 \mathrm{~g} /$ day, $P=0.01)$, cereals $(-3.4 \mathrm{~g} /$ day, $P=0.03)$, poultry $(-0.8 \mathrm{~g} /$ day, $P=$ $\left.6 \times 10^{-3}\right)$, and wine $(-4.8 \mathrm{~g} /$ day, $P=0.03)$ but with higher consumption of potatoes $\left(3.0 \mathrm{~g} /\right.$ day, $\left.P=5 \times 10^{-3}\right)$ in European individuals [20]. An association between the 
milk intake increasing allele of rs4988235 and lower consumption of fruits as well as vegetables was also observed in a Danish population [50]. There is some evidence that low consumption of fruits and vegetables might increase the risk of colorectal cancer $[5,7]$. Thus, any effect of fruit and vegetable consumption would be expected to attenuate the association between genetically predicted milk consumption and risk of colorectal cancer towards the null and cannot explain our finding.

The milk intake increasing allele of rs4988235 has also been associated with higher body mass index in several studies [51-53] but not all [20,21], as well as positively associated with height [54]. Considering that greater body mass index and height are associated with an increased risk of colorectal cancer [55, 56], these factors also cannot mediate the inverse association between genetically predicted milk consumption and colorectal cancer. Rs4988235 is not associated with other potential colorectal cancer risk factors, such as red meat, processed meat, and alcohol consumption, type 2 diabetes, physical activity, and smoking, and is also not associated with education level in European individuals [20, 21, 50].

Variations in allele frequency of the lactase persistence variant across populations can lead to population stratification bias. In this MR study, we reduced such bias by confining the analyses to individuals of European ancestry. Furthermore, all studies adjusted for population substructure through genetic principal components. Results for genetically predicted milk consumption and colorectal cancer risk were also consistent in the relatively homogenous study sample of Finnish participants included in the FinnGen consortium, suggesting that population stratification bias is unlikely to explain this association. A possible explanation for the observed positive association between genetically predicted milk consumption and prostate cancer risk in FinnGen might be related to that the FinnGen population is more homogenous than the populations in the other two data sources.

\section{Conclusions}

Our findings strengthen the evidence for a protective role of milk consumption on colorectal cancer risk. There was no or limited evidence that milk consumption affects the risk of bladder, breast, and prostate cancer.

\section{Abbreviations}

BCAC: Breast Cancer Association Consortium; Cl: Confidence interval; OR: Odds ratio; PRACTICAL: Prostate Cancer Association Group to Investigate Cancer Associated Alterations in the Genome; SNP: Single nucleotide polymorphisms

\section{Acknowledgements}

This research has been conducted using the UK Biobank Resource under Application number 29202. The authors acknowledge the use of summarylevel data from the FinnGen consortium, BCAC, and PRACTICAL consortium.

\section{Authors' contributions}

SCL had full access to all of the data in the study and takes responsibility for the integrity of the data and the accuracy of the data analysis. SCL designed the study, acquired the data, performed the statistical analysis, and drafted the manuscript. SCL, AMM, SK, MV, PC, JAB, KM, and SB interpreted the data and critically revised the manuscript for important intellectual content. All authors read and approved the final manuscript.

\section{Funding}

Susanna C. Larsson is supported by research grants from the Swedish Research Council for Health, Working Life and Welfare (Forte; 2018-00123), the Swedish Research Council (Vetenskapsrådet; 2019-00977), and the Swedish Heart-Lung Foundation (Hjärt-Lungfonden; 20190247). Siddhartha Kar is supported by a Cancer Research UK programme grant, the Integrative Cancer Epidemiology Programme (C18281/A19169). Amy M. Mason is supported by EC-Innovative Medicines Initiative (BigData@Heart). Stephen Burgess is supported by Sir Henry Dale Fellowship jointly funded by the Wellcome Trust and the Royal Society (204623/Z/16/Z). This work was supported by funding from the National Institute for Health Research [Cambridge Biomedical Research Centre at the Cambridge University Hospitals NHS Foundation Trust] [*]. *The views expressed are those of the authors and not necessarily those of the NHS, the NIHR, or the Department of Health and Social Care. Open Access funding provided by Karolinska Institute.

\section{Availability of data and materials}

Information on how to obtain summary-level data from the FinnGen consortium, the BCAC, and the PRACTICAL consortium is available at https://finngen.gitbook. io/documentation/, http://bcac.ccge.medschl.cam.ac.uk/, and http://practical.icr.ac. uk/blog/, respectively. Access to the UK Biobank data can be obtained upon application (https://www.ukbiobank.ac.uk/). Summary-level data analyzed in this study can be obtained from the corresponding author upon reasonable request.

\section{Ethics approval and consent to participate}

The UK Biobank and studies included in the consortia were approved by an ethical review board, and all participants provided informed consent. The current analyses were approved by the Swedish Ethical Review Authority.

\section{Consent for publication}

Not applicable.

\section{Competing interests}

The authors declare that they have no competing interests.

\section{Author details}

${ }^{1}$ Unit of Medical Epidemiology, Department of Surgical Sciences, Uppsala University, Uppsala, Sweden. ${ }^{2}$ Unit of Cardiovascular and Nutritional Epidemiology, Institute of Environmental Medicine, Karolinska Institutet, 17177 Stockholm, Sweden. ${ }^{3}$ British Heart Foundation Cardiovascular Epidemiology Unit, Department of Public Health and Primary Care, University of Cambridge, Cambridge, UK. ${ }^{4}$ National Institute for Health Research Cambridge Biomedical Research Centre, University of Cambridge and Cambridge University Hospitals, Cambridge, UK. ${ }^{5} \mathrm{MRC}$ Integrative Epidemiology Unit, Bristol Medical School, University of Bristol, Bristol, UK. ${ }^{6} \mathrm{MRC}$ Cancer Unit, University of Cambridge, Cambridge, UK. ${ }^{7}$ Department of Public Health and Primary Care, University of Cambridge, Cambridge, UK. ${ }^{8}$ Department of Epidemiology, Geisel School of Medicine at Dartmouth, Hanover, NH, USA. ${ }^{9}$ Department of Medicine, University of North Carolina School of Medicine, Chapel Hill, NC, USA. ${ }^{10}$ Department of Epidemiology, Gillings School of Global Public Health, University of North Carolina, Chapel Hill, NC, USA. ${ }^{11}$ MRC Biostatistics Unit, University of Cambridge, Cambridge, UK.

Received: 18 August 2020 Accepted: 3 November 2020 Published online: 02 December 2020

\section{References}

1. Willett WC, Ludwig DS. Milk and health. N Engl J Med. 2020;382:644-54.

2. Cho E, Smith-Warner SA, Spiegelman D, Beeson WL, van den Brandt PA, Colditz GA, Folsom AR, et al. Dairy foods, calcium, and colorectal cancer: a pooled analysis of 10 cohort studies. J Natl Cancer Inst. 2004;96:1015-22. 
3. Aune D, Lau R, Chan DS, Vieira R, Greenwood DC, Kampman E, Norat T. Dairy products and colorectal cancer risk: a systematic review and metaanalysis of cohort studies. Ann Oncol. 2012;23:37-45.

4. Thorning TK, Raben A, Tholstrup T, Soedamah-Muthu SS, Givens I, Astrup A. Milk and dairy products: good or bad for human health? An assessment of the totality of scientific evidence. Food Nutr Res. 2016;60:32527.

5. Vieira AR, Abar L, Chan DSM, Vingeliene S, Polemiti E, Stevens C, Greenwood D, et al. Foods and beverages and colorectal cancer risk: a systematic review and meta-analysis of cohort studies, an update of the evidence of the WCRF-AICR Continuous Update Project. Ann Oncol. 2017; 28:1788-802.

6. Barrubes L, Babio N, Becerra-Tomas N, Rosique-Esteban N, Salas-Salvado J. Association between dairy product consumption and colorectal cancer risk in adults: a systematic review and meta-analysis of epidemiologic studies. Adv Nutr. 2019;10:S190-211.

7. World Cancer Research Fund/American Institute for Cancer Research. Diet, nutrition, physical activity and cancer: a global perspective. The Third Expert Report:: World Cancer Research Fund International; 2018.

8. Veettil SK, Ching SM, Lim KG, Saokaew S, Phisalprapa P, Chaiyakunapruk N. Effects of calcium on the incidence of recurrent colorectal adenomas: a systematic review with meta-analysis and trial sequential analysis of randomized controlled trials. Medicine (Baltimore). 2017;96:e7661.

9. Heine-Broring RC, Winkels RM, Renkema JM, Kragt L, van Orten-Luiten AC, Tigchelaar EF, Chan DS, et al. Dietary supplement use and colorectal cancer risk: a systematic review and meta-analyses of prospective cohort studies. Int J Cancer. 2015;136:2388-401.

10. Chau R, Dashti SG, Ait Ouakrim D, Buchanan DD, Clendenning M, Rosty C, Winship IM, et al. Multivitamin, calcium and folic acid supplements and the risk of colorectal cancer in Lynch syndrome. Int J Epidemiol. 2016;45:940-53.

11. Wu J, Yu Y, Huang L, Li Z, Guo P, Xu YW. Dairy product consumption and bladder cancer risk: a meta-analysis. Nutr Cancer. 2020;72:377-85.

12. Bermejo LM, Lopez-Plaza B, Santurino C, Cavero-Redondo I, Gomez-Candela C. Milk and dairy product consumption and bladder cancer risk: a systematic review and meta-analysis of observational studies. Adv Nutr. 2019;10:5224-38

13. Wu J, Zeng R, Huang J, Li X, Zhang J, Ho JC, Zheng Y. Dietary protein sources and incidence of breast cancer: a dose-response meta-analysis of prospective studies. Nutrients. 2016;8.

14. Zang J, Shen M, Du S, Chen T, Zou S. The association between dairy intake and breast cancer in Western and Asian populations: a systematic review and meta-analysis. J Breast Cancer. 2015;18:313-22.

15. Aune D, Navarro Rosenblatt DA, Chan DS, Vieira AR, Vieira R, Greenwood DC, Vatten $L J$, et al. Dairy products, calcium, and prostate cancer risk: a systematic review and meta-analysis of cohort studies. Am J Clin Nutr. 2015; 101:87-117.

16. Lopez-Plaza B, Bermejo LM, Santurino C, Cavero-Redondo I, Alvarez-Bueno C, Gomez-Candela C. Milk and dairy product consumption and prostate cancer risk and mortality: an overview of systematic reviews and metaanalyses. Adv Nutr. 2019;10:S212-23.

17. Markozannes G, Tzoulaki I, Karli D, Evangelou E, Ntzani E, Gunter MJ, Norat T, et al. Diet, body size, physical activity and risk of prostate cancer: an umbrella review of the evidence. Eur J Cancer. 2016;69:61-9.

18. Godos J, Tieri M, Ghelfi F, Titta L, Marventano S, Lafranconi A, Gambera A, et al. Dairy foods and health: an umbrella review of observational studies. Int J Food Sci Nutr. 2020;71:138-51.

19. Genkinger JM, Hunter DJ, Spiegelman D, Anderson KE, Arslan A, Beeson WL, Buring JE, et al. Dairy products and ovarian cancer: a pooled analysis of 12 cohort studies. Cancer Epidemiol Biomark Prev. 2006;15:364-72.

20. Vissers LET, Sluijs I, van der Schouw YT, Forouhi NG, Imamura F, Burgess $S$, Barricarte A, et al. Dairy product intake and risk of type 2 diabetes in EPICInterAct: a Mendelian randomization study. Diabetes Care. 2019;42:568-75.

21. Bergholdt HKM, Larsen MK, Varbo A, Nordestgaard BG, Ellervik C. Lactase persistence, milk intake, hip fracture and bone mineral density: a study of 97 811 Danish individuals and a meta-analysis. J Intern Med. 2018;284:254-69.

22. Sudlow C, Gallacher J, Allen N, Beral V, Burton P, Danesh J, Downey P, et al. UK biobank: an open access resource for identifying the causes of a wide range of complex diseases of middle and old age. PLoS Med. 2015;12:e1001779.

23. Larsson SC, Carter P, Kar S, Vithayathil M, Mason AM, Michaelsson K, Burgess S. Smoking, alcohol consumption, and cancer: a mendelian randomisation study in UK Biobank and international genetic consortia participants. PLoS Med. 2020;17:e1003178.
24. FinnGen consortium. FinnGen Documentation of R3 release, 2020. Web: https://finngen.gitbook.io/documentation/ [Accessed 31 July 2020].

25. Michailidou K, Lindstrom S, Dennis J, Beesley J, Hui S, Kar S, Lemacon A, et al. Association analysis identifies 65 new breast cancer risk loci. Nature. 2017;551:92-4.

26. Schumacher FR, Al Olama AA, Berndt SI, Benlloch S, Ahmed M, Saunders EJ, Dadaev T, et al. Association analyses of more than 140,000 men identify 63 new prostate cancer susceptibility loci. Nat Genet. 2018;50:928-36.

27. Smith CE, Coltell O, Sorli JV, Estruch R, Martinez-Gonzalez MA, Salas-Salvado J, Fito M, et al. Associations of the MCM6-rs3754686 proxy for milk intake in Mediterranean and American populations with cardiovascular biomarkers, disease and mortality: Mendelian randomization. Sci Rep. 2016;6:33188.

28. Machiela MJ, Chanock SJ. LDlink: a web-based application for exploring population-specific haplotype structure and linking correlated alleles of possible functional variants. Bioinformatics. 2015;31:3555-7.

29. Higgins JP, Thompson SG, Deeks JJ, Altman DG. Measuring inconsistency in meta-analyses. BMJ. 2003;327:557-60.

30. Larsson SC, Andersson SO, Johansson JE, Wolk A. Cultured milk, yogurt, and dairy intake in relation to bladder cancer risk in a prospective study of Swedish women and men. Am J Clin Nutr. 2008;88:1083-7.

31. Gencdal G, Salman E, Ozutemiz O, Akarca US. Association of LCT-13910 C/T polymorphism and colorectal cancer. Ann Coloproctol. 2017;33:169-72.

32. Tarabra E, Pazienza P, Borghesio E, Actis GC, Tappero G, Framarin L, Ayoubi M, et al. LCT-13910C>T polymorphism-associated lactose malabsorption and risk for colorectal cancer in Italy. Dig Liver Dis. 2010;42:741-3.

33. Travis RC, Appleby PN, Siddiq A, Allen NE, Kaaks R, Canzian F, Feller S, et al. Genetic variation in the lactase gene, dairy product intake and risk for prostate cancer in the European prospective investigation into cancer and nutrition. Int J Cancer. 2013;132:1901-10.

34. Torniainen S, Hedelin M, Autio V, Rasinpera H, Balter KA, Klint A, Bellocco R, et al. Lactase persistence, dietary intake of milk, and the risk for prostate cancer in Sweden and Finland. Cancer Epidemiol Biomark Prev. 2007;16: 956-61.

35. FAOSTAT, Food supply - livestock and fish primary equivalent. www.fao.org. Accessed 12 Sept 2020.

36. Baron JA, Barry EL, Mott LA, Rees JR, Sandler RS, Snover DC, Bostick RM, et al. A trial of calcium and vitamin D for the prevention of colorectal adenomas. N Engl J Med. 2015;373:1519-30.

37. Norat T, Riboli E. Dairy products and colorectal cancer. A review of possible mechanisms and epidemiological evidence. Eur J Clin Nutr. 2003;57:1-17.

38. Pufulete M. Intake of dairy products and risk of colorectal neoplasia. Nutr Res Rev. 2008;21:56-67.

39. Yang W, Liu L, Masugi Y, Qian ZR, Nishihara R, Keum N, Wu K, et al. Calcium intake and risk of colorectal cancer according to expression status of calcium-sensing receptor (CASR). Gut. 2018;67:1475-83.

40. Mandle HB, Jahan FA, Bostick RM, Baron JA, Barry EL, Yacoub R, Merrill J, et al. Effects of supplemental calcium and vitamin $D$ on tight-junction proteins and mucin-12 expression in the normal rectal mucosa of colorectal adenoma patients. Mol Carcinog. 2019;58:1279-90.

41. Tsuda H, Kozu T, linuma G, Ohashi Y, Saito Y, Saito D, Akasu T, et al. Cancer prevention by bovine lactoferrin: from animal studies to human trial. Biometals. 2010;23:399-409.

42. Mansson HL. Fatty acids in bovine milk fat. Food Nutr Res. 2008;52:1:1821.

43. Larsson SC, Bergkvist L, Wolk A. High-fat dairy food and conjugated linoleic acid intakes in relation to colorectal cancer incidence in the Swedish Mammography Cohort. Am J Clin Nutr. 2005;82:894-900.

44. Kozu T, linuma G, Ohashi Y, Saito Y, Akasu T, Saito D, Alexander DB, et al. Effect of orally administered bovine lactoferrin on the growth of adenomatous colorectal polyps in a randomized, placebo-controlled clinical trial. Cancer Prev Res (Phila). 2009;2:975-83.

45. Liu Y, Ajami NJ, El-Serag HB, Hair C, Graham DY, White DL, Chen L, et al. Dietary quality and the colonic mucosa-associated gut microbiome in humans. Am J Clin Nutr. 2019;110:701-12.

46. Guantario B, Giribaldi M, Devirgiliis C, Finamore A, Colombino E, Capucchio MT, Evangelista R, et al. A comprehensive evaluation of the impact of bovine milk containing different beta-casein profiles on gut health of ageing mice. Nutrients. 2020;12:2147.

47. Harrison S, Lennon R, Holly J, Higgins JPT, Gardner M, Perks C, Gaunt T, et al. Does milk intake promote prostate cancer initiation or progression via effects on insulin-like growth factors (IGFs)? A systematic review and metaanalysis. Cancer Causes Control. 2017;28:497-528. 
48. Larsson SC, Carter P, Vithayathil M, Kar S, Mason AM, Burgess S. Insulin-like growth factor-1 and site-specific cancers: a Mendelian randomization study. Cancer Med. 2020.

49. Wilson KM, Shui IM, Mucci LA, Giovannucci E. Calcium and phosphorus intake and prostate cancer risk: a 24-y follow-up study. Am J Clin Nutr. 2015; 101:173-83.

50. Bergholdt HK, Nordestgaard BG, Varbo A, Ellervik C. Milk intake is not associated with ischaemic heart disease in observational or Mendelian randomization analyses in 98,529 Danish adults. Int J Epidemiol. 2015;44: 587-603.

51. Mendelian Randomization of Dairy Consumption Working G. Dairy consumption and body mass index among adults: Mendelian randomization analysis of 184802 individuals from 25 studies. Clin Chem. 2018;64:183-91.

52. Yang $\mathrm{Q}$, Lin SL, Au Yeung SL, Kwok MK, Xu L, Leung GM, Schooling CM. Genetically predicted milk consumption and bone health, ischemic heart disease and type 2 diabetes: a Mendelian randomization study. Eur J Clin Nutr. 2017;71:1008-12.

53. Hartwig FP, Horta BL, Smith GD, de Mola CL, Victora CG. Association of lactase persistence genotype with milk consumption, obesity and blood pressure: a Mendelian randomization study in the 1982 Pelotas (Brazil) Birth Cohort, with a systematic review and meta-analysis. Int J Epidemiol. 2016(45):1573-87.

54. Wood AR, Esko T, Yang J, Vedantam S, Pers TH, Gustafsson S, Chu AY, et al. Defining the role of common variation in the genomic and biological architecture of adult human height. Nat Genet. 2014:46:1173-86.

55. Cornish AJ, Law PJ, Timofeeva M, Palin K, Farrington SM, Palles C, Jenkins MA, et al. Modifiable pathways for colorectal cancer: a mendelian randomisation analysis. Lancet Gastroenterol Hepatol. 2020;5:55-62.

56. Lai FY, Nath M, Hamby SE, Thompson JR, Nelson CP, Samani NJ. Adult height and risk of 50 diseases: a combined epidemiological and genetic analysis. BMC Med. 2018;16:187.

\section{Publisher's Note}

Springer Nature remains neutral with regard to jurisdictional claims in published maps and institutional affiliations.

Ready to submit your research? Choose BMC and benefit from:

- fast, convenient online submission

- thorough peer review by experienced researchers in your field

- rapid publication on acceptance

- support for research data, including large and complex data types

- gold Open Access which fosters wider collaboration and increased citations

- maximum visibility for your research: over $100 \mathrm{M}$ website views per year

At $\mathrm{BMC}$, research is always in progress.

Learn more biomedcentral.com/submissions 